\title{
Revisiting Ragnar Frisch on the negative marginal tax rate and the socially optimal amount of work
}

Romar Correa ${ }^{1}$

\begin{abstract}
We appraise Agnar Sandmo's recent study of the theme. Our criterion is macroeconomic theory. Consequently, spillovers between agents and markets are central to our rewrite. We show that an increase in the tax rate on wage income increases hours worked and thereby raises output and employment.
\end{abstract}

Keywords: worker taxation, effort, spillover effects

JEL classification: B13, B31, E12, E60

\section{Introduction}

As the world-wide recession persists, the age-old problem of defining unemployment equilibrium is underscored. The benchmark of all mainstream models remains the starred value of the level of output and actual output is assumed to tend towards the market-clearing level. Price, notably wage, stickiness are roadblocks on that path. However, since expressions like "secular stagnation" become common coin across leading scholars across the methodological spectrum, the search for coherent explanations and optimal policy arrangements becomes urgent. Macroeconomic policy has become more or less synonymous with monetary policy. At heart, the classical neutrality and dichotomy theorems are still held. Markets are believed to be the best of the possible institutions in the absence of workable arrangements to the contrary. In that case, the optimal level of output is generated by the freedom of people to "truck, barter and exchange". The fiscal authority must be a minimal state addressing only the well-known cases of "market failure". Accordingly, the yardstick here is budget balance. Under the extraordinary circumstances of the times as well as, independently, the deterioration of physical and social infrastructure across the developed and the underdeveloped world, the expenditure side of the budget is a topic of academic and popular concern. Thus, blueprints for large projects are being drawn up in the US and Europe. The eventual budgetary implications worry framers because the theory of income taxation seems to offer no fresh ideas on balance. Economists have stayed with the negative work inducement effects of increased taxation and only serious philosophers and some sociologists have found the topic worthy of interest in the social economy-wide ramifications of systems of taxation.

Ragnar Frisch was a great scholar of economic change and microeconomic reasoning. Students of dynamics must return to the seminal paper or two by him for understanding the true meaning of the term. His pioneering contributions to rigorous policy interventions were less known because the English-speaking world did not benefit from their translation. Agnar Sandmo, 2017, has therefore rendered yeoman's service in bringing to light his insights into a topic that cannot be more relevant to modern times. Considering the pedigree of this illustrious Norwegian economist, his exposition merits equal serious attention as well. 
We synthesise the insights of the two giants as well as add our interpretation of their analysis.

\section{A micro-macro metric}

Frisch sought to explain the phenomenon of suboptimal employment. While there may be equilibrium in the labour market, actual employment is short of the quantity required to maximize the social surplus. The maximum social surplus is that which maximizes the sum of the utilities of all economic agents. Already the element of spillovers arises as interpersonal comparisons of utility cannot be disregarded. The objective of the policy intervention being examined is to bring total output in congruence with the maximization of the utilities of all members of society. A macroeconomic orientation is supported by recent advocacies of a sea change in thinking about the philosophy of taxation (Silvestri, 2015). The tax system in these proposals is the node of a social contract that is at the intersection point of lateral and vertical relationships, between citizens, and between citizens and government. Our treatment below can be regarded as the join between the benefit-cost principle and the ability-to-pay principle. With regard to the latter and in the context of a recession, taxation of wage income should be 'optimal'. In macroeconomic translation, wage increases must go hand-in-glove with productivity increases. Concerning the former, some studies have unearthed a connection between taxpayers' willingness to pay taxes with the ability to track how the collected resources are spent (Flores-Macias, 2016). While there might be a minority case for secrecy in the deliberations of monetary policy committees, in the case of all elements of fiscal policy there is a consensus on transparency and disclosure. As in the case of "people's audits" in some countries, civil society monitoring committees are formed to follow the expenditure of revenues from income taxes. Uncertainty and mistrust is reduced when expenditures are seen to correspond to the preferences of the general populace.

Professor Sandmo reports that Professor Frisch vacillated between the production unit as a household and as a firm. In the latter case, he moved between a firm and the sector to which it belonged. His definitions of internal and external productivity were concerned with different levels of aggregation. Also, the underlying orientation seemed to be the theory of externalities and public economics. From the broad neighborhood, we recall the long line of French ingénieur-economists who founded the theory of project appraisal and went on to write the basics in the theory of public economics. We, on the other hand, find echoes of Frisch in the economics of Keynes, in macroeconomics. Frisch worked with the net wage rate, the real wage net of the marginal tax rate as a policy composite. He rightly intuited that the relative strengths of the income and substitution effects would determine the direction of labour supply. His attention was directed no less to the wage rate than to the tax rate to the extent of entertaining the former as a policy variable as well. Thus, Agnar Sandmo illuminates the tensions in Ragnar Frisch in juggling with the implications of competition and the attractions of global optima afforded by central planning solutions. The modern debate revolves around a "living wage" that must be associated with "decent work" (Carr et al, 2016). Living wages are often legislated. Our common expectation, on the other hand, is that an "optimal" wage will lead to increased consumption and employment and further to motivation and increased productivity at workplaces. In multi-market terms, outcomes in the labour market disturb the equilibrium in the commodities market. In order to distinguish our micro-grounded macro with partial equilibrium analysis we note the difference between perfect/imperfect information and asymmetric information. The former is public, the latter private. No better scenario than the post-war reconstruction efforts that inspired Professor Frisch to make the general point that shortages or gluts will impact on all agents. Coming to the specific situation of a recession that endures, the stockpiling of goods and people seeking work at the factory gates is common knowledge. At worst, this perfect information might pick up noise on its way to the statistics desks of policy makers or planners, becoming imperfect. Secondly, the information explosion in the hands of the authorities backed by a regime of random auditing and stiff penalties accepted by people because strictly implemented would induce tax compliance. At the same time, herd behavior might prevail locally (Alm, 2017). If one's peers are not truthfully revealing their income and meet with success, 
the representative agent might be motivated to follow suit.

Frisch worked with cardinal utility functions so he did not see the need to incorporate the marginal rate of substitution between consumption and leisure in his calculations. It turns out that that distinction with ordinality is not relevant in his treatment. In any case, the status report is that the utilitarian starting point was abandoned early (Hoover, 2016). Vilfredo Pareto and others all the way to Lionel Robbins replaced cardinal utility with ordinal utility and rendered the utility function inconsequential. All the same, there are checks and balances that we need to impose on our treatment in either instance. Katzner \& Skott, 2004 , is the summary of a scholarly discussion surrounding the capture of efficiency in efficiency wage models. In the work of Joseph E. Stiglitz notably the theory was used to suggest Keynestype outcomes. Stiglitz arrangements are bilateral contracts emerging from the asymmetric information that characterizes principals and agents. Credit rationing, for instance, emerges from the inability of banks to discriminate between the prospectuses of "blue-eyed" and high-risk borrowers. In the case of interest to us, the efficiency wage would be higher than the market-clearing wage so as to induce higher effort. The literature referred to in the Katzner \& Skott survey shows that the movement from the production function of microeconomics to the "production function" of efficiency wage theory is hazardous. At the heart of the problem is the measurement of "effort". Both with Frisch and our interpretation, the knotty issue of the measurement of variables is circumvented when dealing with working hours. While leisure might be a slippery concept to pin down, when total time is specified and the residual from the time spent in the factory is termed leisure we are on safe ground.

\section{The Frisch production function: a reformulation}

Our basic representative consumer-worker utility maximization problem is no different from that posed by Sandmo (2017: 9). Our problem below corresponds to his equation (6). Denoting by $T$, total time available; by $l$, the time allocated to leisure; $T-l=x$ is the consumer's supply of working hours; the price of the single commodity is $p$ and the wage rate is $w$. In that case, the program of the representative agent is to
Maximize $u(c, l)$ subject to $p c \leq w x$

The solution is given by the following two equations

$$
\begin{aligned}
& \frac{u^{\prime}}{u^{\prime}}=\frac{p}{w} \\
& w x^{*}=p c^{*}
\end{aligned}
$$

While interpersonal utility comparisons are sufficient they are not necessary (Hoover, 2016). From Jeremy Bentham through Stanley Jevons, only intrapersonal comparisons of utility are needed to derive exchange ratios. Exchange value is the same as relative price. Moving to the producer characterized by the technological blueprint called a production function $f(x)$, her problem is to maximize profits given by (see also equation (14) in Sandmo (2017: 13)).

$$
\pi(x)=p f(x)-w x
$$

The first-order condition obtained both by him and us is that the flow of labour hours will continue till "internal marginal productivity is equal to the wage rate" (2017:13). Summarizing this first-order condition with that above, equation 1, as does Professor Sandmo with his equations (13) and (15), we have

$$
f^{\prime}(x)=\frac{w}{p}=\frac{u^{\prime}}{u^{\prime}}
$$

We are ready to provide our own interpretations of Frisch's seminal definitions.

DEFINITION 1. "Internal" or "direct productivity" and "external" or "indirect productivity"

Internal or what we call ex ante productivity is the marginal product of labour or the derivative of the production function in equation 4, no different from the definition of Professor Frisch. The redoubtable scholar defines external marginal productivity as the increase in output brought about the efforts of all other workers in the economy which is assumed to act positively on the efforts of our given worker. The production function would have an additional argument with a positive sign denoting the aggregate hours worked by all but the one worker under consideration. The scholar does note that in a large economy the two arguments collapse into one. In contrast, we define external productivity or productivity ex post as the substitution 
of the solution of the worker problem given in equation 2 into the production function. That is $f\left(p c^{*} / w\right)$. We incorporate the feedback effect of the 'other' individual's behavior into the producer's actual production. Feedback can be both positive or negative. The macroeconomic process is precisely the sway of positive feedback from the chosen market to other markets. Indeed, the cumulative upward or downward process is regarded as the defining characteristic of Swedish disequilibrium analysis. Negative feedback is the equilibrating mechanism in microeconomic disturbances. An increase in price results in an increase in quantity supplied and a fall in quantity demanded restoring the original intersection point of the two curves, other things being equal. Our requirement of either sign consistently across the board might be regarded as a snapshot of the cumulative processes associated with the illustrious members of the Stockholm School. Also, adhering to the Katzner- Skott test the 'new look' production function cannot violate the properties of the familiar production function. For instance, the sign of the derivative must be positive. Our function does not appear to possess the technical flavor of an engineering relationship. However, using the first-order condition in the case of the firm, equation 4 , our production function is $f\left(c^{*} / f^{\prime}(x)\right.$ ). (we have now used all the requirements of the multi-market equilibrium). Assuming a concave production function, $f^{\prime}(x) \geq 0$. In the spirit but not the letter of Professor Frisch, the motivation is especially the possibility of emergence from a recession where the smooth working of market $n$ depends on the frictionless working of $n-1$ markets. Underlying the interdependence is the division of labour and the extent of the market. One piece of evidence is that in a model of the equilibrium wage equation for the Eurozone countries, wages are seen to be positively related to productivity and negatively related to unemployment (Camarero et al., 2016). Flexible labour markets are associated with wage restraint. Returning to the theme of Market versus Plan, government interventions tends to accentuate wage moderation as the Plan is a social optimization exercise concerned with wage competitiveness. In the present instance, there was a break in the long-run relationships in 2004 because of which increased labour market flexibility and international competition led to greater sensitivity of the long-run real wage to productivity.

We can our flesh out our definition further by a well-known compositional counter-intu- ition associated with Keynes. Taking the derivative of the profit function equation 3 with respect to the wage rate we get a negative expression, $-x$. Reverting to another famous distinction, equation 3 is "notional". In contrast, we have "effective" demand. An increase in the wage rate is cost to an individual producer but income to a worker. In the aggregate, an increase in wages and consequent demand spills over into increased profits. In the present case, an increase in hours worked increases the income of the worker. Writing our producer maximand equation 3 ex post, incorporating the solution of the consumer-worker problem equation 2 , we have

$$
\pi(x)=p f\left(c^{*} / f^{\prime}(x)\right)-p c^{*}
$$

With a concave production function used earlier, we get $\partial \pi / \partial x \geq 0$. Both consumer/ worker and producer are better off. Higher income does not higher welfare make except under the emphasis of Ragnar Frisch that the greater number of hours worked and the higher wages that flow consequently would be spent on an array of consumer goods. We have an early empirical forecast of what would later turn out to be a foundational assumption of Post Keynesian economics in the difference between the propensities to consume of capitalists and workers. Consumer basics might even have to be imported without in any way detracting from the accumulation of capital that was the hallmark of the postwar reconstruction efforts.

\section{Taxation and work}

The aspect of taxation on the table below is "horizontal equity" a principle largely regarded as incontrovertible by taxation experts. Equals must be treated equally. However, in searches for empirical validation of this conjecture, wide variations have been found in tax rates and consumption patterns within income groups (Alm, 2017). The broad conclusion is that households within the same income bracket might have different preference schedules, affecting the incidence of taxation. To introduce taxation we have a tax rate of $t$, the worker's take-home real wage then becoming $(1-t) w x$. To $w$ in all the expressions and optimality conditions above we multiply (1 $t$ ). Looking to equation 2, we find that $\partial x^{*} / \partial t$ 
$\geq 0$. The income tax is an incentive to work. The logic seems elementary. The tax reduces disposable income. Consumption and enjoyment of leisure not being inferior goods fall. Due to the latter, hours worked increase. It is a straightforward matter to consider the mirror situation of a tax subsidy paid out to firms as Professor Sandmo does. From equation 3, we get $\partial \pi / \partial t \geq 0$. At the cost of repetition we observe that the positive effects are consistent with each other. In contrast, Professor Frisch effectively separates out $t$ in the after-tax wage in equation 2 and gets a negative expression for it. Our difference in signs might be due to the level effect in his case and the calculation of a derivate in ours. We concede that Professor Frisch distinguishes between a tax imposed on income and in fact recommends a progressive structure there and a tax that is effort-neutral. Professor Sandmo translates a nuanced discussion of the connection between the two by Professor Frisch. Our treatment is standard microeconomics and to that extent is one-dimensional.

Our formulation, particularly the specification of an underemployment equilibrium, would be assisted by a move to indirect utility functions. Accordingly,

DEFINITION 2. The indirect utility function $v(p, w)=$ maximum value of $u(c, l)$ subject to $p c \leq w x$.

Likewise, without any confusion with the earlier 'traditional' profit function, we have

DEFINITION 3. The profit function

$\pi(p, w)=$ maximum value of $p f(x)-w x$.

DEFINITION 4. We define a social equilibrium as a pair $\left(p^{*}, w^{*}\right)$ such that

$$
\begin{aligned}
& v\left(p^{*}, w^{*}\right) \geq v(p, w) \\
& \pi\left(p^{*}, w^{*}\right) \geq \pi(p, w)
\end{aligned}
$$

In order to check that our movement from direct to indirect utility functions does not fall foul of the Katzner-Skott criterion, we rely on the properties of the functions given above. The indirect utility function is homogenous of degree zero in the arguments and the profit function is homogenous of degree one in the arguments. But first we need to provide Roy's Identity in our case. It states

$$
\frac{\frac{\partial v}{\partial w}}{\frac{\partial v}{\partial p}}=\frac{p}{w}
$$

By Euler's theorem we have

$$
\frac{\partial v}{\partial w}+w \frac{\partial v}{\partial p} p=v(p, w)
$$

Substituting equation 6 into equation 7 we indeed get

In the case of the producer the theorem is

$$
\frac{\partial \pi}{\partial w} w+\frac{\partial \pi}{\partial p} p=0
$$

Taking the derivatives called for in equation 5 and plugging them into equation 8 we confirm

$$
w x^{*}-p c^{*}=0
$$

We have not had occasion to specify the maximal level of output given by the full employment of labour via the production function. Indeed, with the novel production function originating with Professor Frisch, the equality of what we might term the inter marginal product of labour with the wage is unlikely to hold. Since the consumer-worker and producer problems interlock, it is natural to consider the social equilibrium as applying to a level of output less than the full employment level.

\section{Conclusion}

Ragnar Frisch grappled with the problem of reconstructing an economy from the deterioration of human and material resources. As an academic, he needed to define an equilibrium that was suboptimal and inefficient. Once having done so, remarkably he did not attend to the problem as Keynes would have done through the medium of government expenditure. Both were concerned with the collapse of economic endeavour when the firing of that side of the government budget would have been the natural response. A partial explanation might be Joan Robinson's unconfirmed quip attributed to Gerald Shove, also apocryphal, that Keynes "never spent the twenty minutes necessary to understand the theory of value". Keynes was eloquent in his testimony for public works to employ desperately-willing hands. His powerful polemics found sympathetic ears in the political heads of the capitalist world of the day. In contrast, Professor Frisch dug into human incentives through the device of direct taxes impacting on work efforts. Only a master the- 
orist would have the confidence to originate a social interpretation of a technological construct, the production function. Ragnar Frisch invented what we have called the inter marginal productivity of labour. We have no more than entered spaces opened by him respectfully noting that our standard account cannot capture all the nuances of his historical-cum-an- alytical exegesis of his country. In a structural account, we need to trace the effects from workers and consumers to producers and back, from the workplace to the factory to the retail store and back again. Only then is the Pareto improvement of the existing social equilibrium proved and the basis of a virtuous cycle laid.

\section{References}

Alm, J. 2017. Is Economics Useful for Public Policy?, Tulane Economics Working Paper 1702.

Camarero, M., G. d'Adamo and C. Tamarit, 2016. The role of institutions in explaining wage relations in the Eurozone: A panel cointegration approach, International Labour Review, (55) 1:25-32.

Carr, S.C., J. Parker, J Arrowsmith and P.A. Watters. 2016. The living wage: Theoretical integration and an applied research agenda, International Labour Review, (55) 1: 1-24.

Flores-Macias, Gustavo A., 2016, Building Support for Taxation in Developing Countries: Experimental Evidence from Mexico, International Centre for Taxation and Development Working Paper 51.

Hoover, K.D., 2016, The crisis in Economic Theory: A review Essay, Journal of Economic Literature, (54): 4, 1350-1361.

Katzner, D.W. and P. Skott, 2004. Economic Explanation, Ordinality and the Adequacy of Analytic Specification, University of Massachusetts Amherst, Department of Economics Working Paper 2004-02.

Sandmo, A., 2017. Should the marginal tax rate be negative? Ragnar Frisch on the socially optimal amount of work, Institutt for Samfunnsøkonomi, Department of Economics, Working Paper 01-2017.

Silvestri, Paolo, 2015, Anthropology of freedom and tax justice: Between exchange and gift. Thoughts for an interdisciplinary research agenda, The Department of Economics and Statistics "Cognetti de Martiis" Working Paper 3/15. 